\title{
MANIFESTAÇÕES PATOLÓGICAS EM CONCRETO ARMADO ESTUDO DE CASO CORROSÃO NAS ARMADURAS
}

\author{
Marcellus Fortes Cerqueira \\ Graduando em Engenharia Civil pela UNISUAM, Rio de Janeiro, RJ, Brasil \\ marcellusfortes@gmail.com \\ Rodrigo Souza Gonçalves \\ Graduando em Engenharia Civil pela UNISUAM, Rio de Janeiro, RJ, Brasil \\ drigosg57@yahoo.com.br \\ Igor Charlles Siqueira Leite \\ Mestre em Engenharia Civil pela COPPE/UFRJ, Rio de Janeiro, RJ \\ engfabigor@gmail.com
}

\section{RESUMO}

Assim como todo e qualquer elemento frágil, uma estrutura de concreto, apesar de aparentemente forte e durável, precisa de atenção, cuidados básicos e manutenção constante. Ocorrências patológicas nessas estruturas é um fenômeno muito comum e de larga incidência e quando este exercício não é feito, muitas vezes é necessário fazer uma manutenção corretiva no edifício para que ele possa ser utilizado novamente, aproveitando $100 \%$ de sua eficiência como estrutura. Uma manutenção preventiva bem planejada reduz os custos com recuperação estrutural, prolonga a vida útil das edificações, reduz transtornos e evitam patologias que põe em risco tanto a construção quanto a saúde dos que ali residem. Este trabalho aponta as origens patológicas nas estruturas de concreto armado, salientando os meios em que a edificação está exposta e as condições que ela se encontra. $O$ estudo de caso apresentado foi realizado no famoso Hotel Nacional, grande estrutura de concreto armado localizada na Praia de São Conrado no RJ, tombada pelo IPHAN e exposta ao meio marítimo. Foram apresentadas armaduras castigadas pela corrosão e perda de seção em diversos pontos das vigas e pilares. Em seguida foi realizada uma análise e proposta uma possível solução para recuperação desta estrutura corroída.

Palavras-chave: Patologias. Estrutura de Concreto. Corrosão das Armaduras.

\section{PATHOLOGICAL MANIFESTATIONS IN REINFORCED CONCRETE CASE STUDY CORROSION IN ARMATURES}

\section{ABSTRACT}


As well as any fragile element, a concrete structure, though apparently strong and durable, needs attention, basic care and constant maintenance. Pathological occurrences in these structures is a very common phenomenon of great incidence and when this is not done corrective maintenance is often required, taking advantage of $100 \%$ of their efficiency as a structure. Well-planned preventive maintenance reduces costs with structural recovery, extends the life of buildings, reduces disturbances, and avoids pathologies that endanger both construction and the health of the building. This work points out as pathological origins in the structures of reinforced concrete, emphasizing the means in which the building is exposed and as conditions that it is found. The presented case study in the famous National Hotel, a large reinforced concrete structure located on the São Conrado Beach in RJ, heritage listed by IPHAN and exposed to the marine environment. Corrosion-reinforced armor and loss of production at various points of the beams and columns were presented. An analysis was performed and a solution was proposed for the recovery of this corroded structure

Keywords: Pathologies. Concrete Structure. Corrosion in Reinforcement.

\section{INTRODUÇÃO}

Muitas patologias que encontramos nas edificações são ligadas a qualidade do material utilizado e modo de execução de serviço. Com o passar dos anos a tecnologia da construção civil tem crescido muito, novas formas e maneiras de execução e novos tipos de material contribuem para que os riscos de má qualidade no produto final sejam cada vez menores, mas esses problemas não diminuem nas mesmas proporções do crescimento.

De acordo com levantamento feito pelo Sindicato da Indústria da Construção Civil de Minas Gerias (SindusCon-MG), o crescimento do Setor na última década foi de $52,10 \%$, o que representa um crescimento médio anual de $4,28 \%$ e considerando os últimos 20 anos, o avanço médio anual foi de 2,82\%. (AMORIM, 2014).

A maior parte das edificações é voltada para o mercado consumidor e a cada ano que passa o cliente está mais consciente e informado sobre seus direitos nas áreas de consumo e com isso houve-se a necessidade de voltar às atenções para a qualidade final na construção.

Acredita-se que um bom Sistema de Gestão da Qualidade reduza parte desses problemas patológicos encontrados e reclamados no pós-obra. De acordo com a lei número 10460 de 10 de janeiro de 2002 constituída no código civil artigo 618 diz: ? Nos contratos de empreitadas de edifícios ou outras construções consideráveis, o 
empreiteiro de materiais e execução responderá, durante o prazo irredutível de cinco anos pela solidez e segurança do trabalho, assim em razão dos materiais, como do solo. Deste modo, o desempenho de materiais e a qualidade dos serviços nos processos de construção devem ser avaliados para evitar essas patologias construtivas.

Pesquisas mostram que a patologia mais comum do concreto armado é a corrosão nas armaduras. Segundo HELENE (1992) "ocorrem com maior incidência na fase de uso. Há casos de corrosão de armadura em lajes de forro/piso de apartamentos que se manifestam intensamente, inclusive com colapso parcial, depois de 13 anos do 'Habite-se'”. (HELENE, 1992, p. 21). Dentre os diversos problemas que uma edificação pode apresentar destaca-se a corrosão de sua armadura, que pode estar diretamente ligada a diversos fatores como a relação água/cimento e ao ambiente em que a estrutura está inserida.

\section{REFERENCIAL TEÓRICO}

\subsection{Concreto Armado}

Para construções de grandes estruturas, o Concreto Armado é a técnica mais utilizada em todo o mundo. Composto de Concreto e barras de aço, surgiu com a necessidade de unir resistência a compressão e durabilidade desses dois materiais, respectivamente, resultando numa estrutura que tem como vantagens assumir qualquer forma com rapidez e facilidade, além de proporcionar ao metal uma proteção contra corrosão.

A União do Concreto com a armadura de aço cria um componente resistente ás tensões de compressão e tração devido as características dos dois materiais. Porém, para um bom desempenho do Concreto Armado, não basta apenas combina-los, é necessário que exista aderência entre eles, ou seja, o trabalho de resistir ás tensões tem que ser realizado de maneira conjunta. [Além dessa colaboração, a associação é possível devido ao coeficiente de dilatação térmica de ambos ser, aproximadamente igual? (MARCELLINO,2016).

\subsection{Vida Útil e Durabilidade do Concreto Armado}

Segundo HELENE (2001), nos últimos anos tem crescido o número de estruturas de concreto armado com manifestações patológicas, como resultado do envelhecimento 
precoce das construções existentes. Essas constatações, tanto no âmbito nacional quanto no âmbito internacional, demonstram que as exigências e recomendações existentes nas principais normas de projeto e execução de estruturas de concreto vigentes, até o final do século passado, eram insuficientes.

Definida como sendo a capacidade de resistir a intempéries, ataques químicos, abrasão ou outros processos de deterioração, durabilidade do Concreto Armado vem sendo muito discutida e estudada nos últimos anos. Nota-se que nenhum material é durável devido ás ações ambientais, a microestrutura muda e consequentemente, as propriedades. Quando as propriedades deste material, sob condições de uso, tiverem sido deterioradas de maneira que sua utilização se torna insegura e caro para ser recuperada, pode-se dizer que sua vida útil chegou ao fim.

Durabilidade é o resultado da interação entre estrutura de concreto armado, o ambiente que está exposto, as condições de uso, de operação e de manutenção. Então, não é uma propriedade inerente a estrutura, a armadura ou ao concreto. Podemos identificar diferentes comportamentos em uma mesma estrutura, ou seja, diferentes funções de durabilidade ao tempo e até mesmo da forma de utiliza-la.

Segundo a ABNT NBR 6118:2007, Durabilidade "Consiste na capacidade da estrutura resistir às influências ambientais previstas e definidas em conjunto pelo autor do projeto estrutural e o contratante, no início dos trabalhos de elaboração do projeto".

\subsection{Patologias em Estrutura de Concreto Armado}

Todas as manifestações cuja ocorrência no ciclo de vida da edificação venha prejudicar o desempenho esperado do edifício e suas partes são denominadas Patologias.

DEGUSSA (2008) entende patologia como parte da engenharia que estuda os sintomas, os mecanismos, as causas e as origens dos defeitos das construções civis e à terapia cabe estudar a correção e a solução desses problemas patológicos, inclusive aqueles devidos ao envelhecimento natural.

Para Piancastelli (1997), sendo o concreto armado, um material não inerte, ele se sujeita a alterações, ao longo do tempo, devido a interações entre seus elementos constitutivos (cimento, areia, brita, água e aço), interações entre esses e agentes externos (ácidos, bases, sais, gases e outros) e com materiais que lhe são adicionados (aditivos e adições minerais). 


\subsection{Origem das Manifestações Patológicas}

A origem de uma patologia está relacionada com a etapa da vida da estrutura em que foi criada a predisposição para que agentes desencadeassem seu processo de formação. Das patologias conhecidas, as principais tem origem devido aos seguintes fatores:

- Defeitos de Projeto

- Defeitos de execução

- Erosão de execução

- Má qualidade dos materiais ou uso inadequado

- Sinistros (Incêndios, inundações, acidentes e etc.)

- Manutenção imprópria ou falta

Abaixo, o gráfico 1 apresenta as principais patologias encontradas nas estruturas de concreto armado.

\section{GRÁFICO 1 - PATOLOGIAS NA ESTRUTURA DE CONCRETO ARMADO}

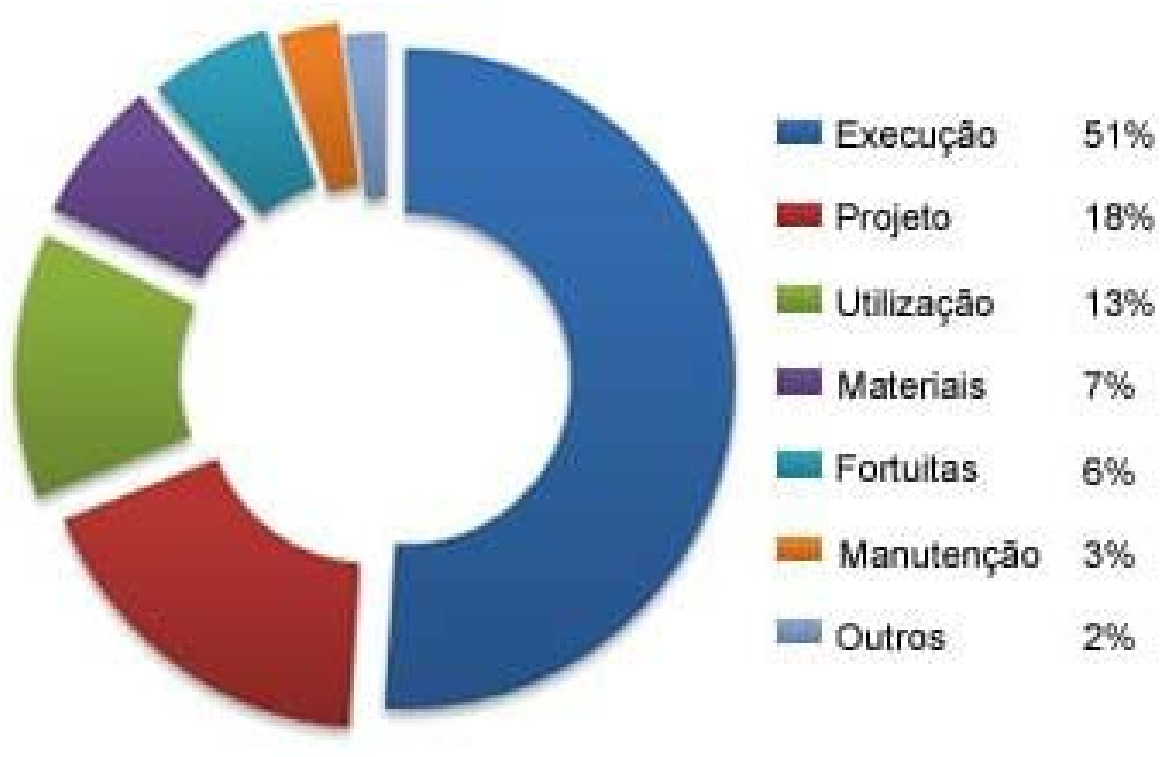

FONTE: (https://www.aecweb.com.br/ , 2017)

"Vale ressaltar que algumas enfermidades são erroneamente consideradas sintomas, como o caso clássico da corrosão das armaduras, que caracteriza a enfermidade 
'falta de homogeneidade', e cujos sintomas são fissuras e disgregação do concreto', diz Piancastelli.

\subsection{Corrosão nas Armaduras}

Mauricio Marcelli, em seu livro "Sinistros na construção civil": causas e soluções para danos e prejuízos em obras afirma:

As trincas em concreto armado devido à corrosão das armaduras são muito comuns em nossas edificações e precisam ser tratadas adequadamente, a fim de bloquear o processo e não as agravar como tem ocorrido em algumas obras, nas quais não se procura identificar, diagnosticar e corrigir as verdadeiras causas do problema. (MARCELLI, 2007)

O processo progressivo de corrosão vai evoluindo com o passar do tempo, por este motivo, as ocorrências não devem ser ignoradas ou tratadas tardiamente para não comprometer a segurança da estrutura e dos que nela habitam.

De acordo com Helene, regiões abertas onde o mar através do vento carrega uma névoa de sais, geralmente perto da costa, faz com que se acelere o processo de corrosão das armaduras. Os ventos podem carregar os sais na forma de partículas sólidas ou como gotas de solução salina contendo vários outros constituintes. A quantidade de sais presente vai diminuindo em função da distância do mar, sofrendo influência da velocidade e direção dos ventos predominantes. A possibilidade de corrosão na atmosfera marinha pode variar de 30 a 40 vezes maior do que na atmosfera rural (HELENE, 1986).

\section{ESTUDO DE CASO}

Este capitulo tem o objetivo de relatar um caso de patologia na estrutura de Concreto Armado no edifício do Hotel Nacional, localizado na Praia de São Conrado no Rio de Janeiro.

Empreendimento inaugurado em 1972 com arquitetura do Oscar Niemeyer, jardins do Burle Marx e projeto estrutural do Bruno Contarini, hoje tombado pelo Patrimônio Histórico do Rio de Janeiro.

O hotel encerrou suas atividades em 1995 e desde então ficou fechado e sem receber qualquer serviço de manutenção predial. Mantem a aparência imponente de um grande projeto arquitetônico, principalmente pelo porte da torre envidraçada com cerca de $100 \mathrm{~m}$ de altura. 
Na figura 1, a maquete eletrônica após a conclusão das obras de reforma do Hotel junto com o futuro Centro de Convenções.

Figura 1 - Maquete eletrônica da obra após Retrofit

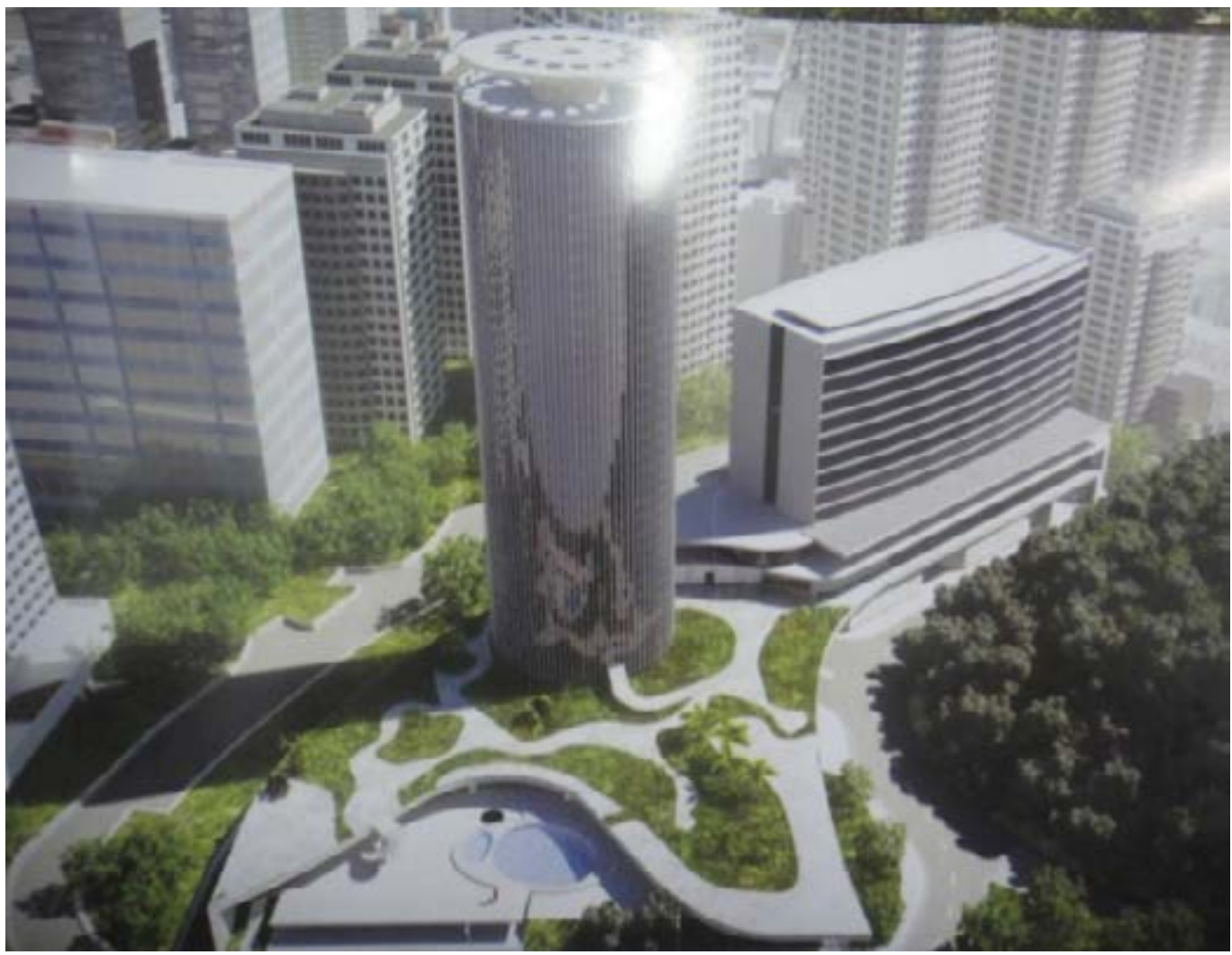

Fonte: (Acervo Hotel Nacional)

Uma empresa de consultoria foi contratada para inspecionar visualmente todas as estruturas em concreto armado na torre do hotel e espaços destinados às instalações de apoio, visando diagnosticar possíveis pontos comprometedores com manifestações patológicas de ordem estrutural ou por outras deficiências como impermeabilizações, corrosões de armaduras ou outros problemas construtivos ou por falta de uso ou manutenção.

Observando o estado geral da edificação, foram identificados pontos localizados de corrosão de armaduras, principalmente onde o concreto armado aparente ficou exposto à maresia. Salienta-se a excelente condição deste concreto que, onde está íntegro, sem brocas ou segregações, que é o caso da grande marquise frontal, não apresenta nem espessura de carbonatação, resultado do ataque do dióxido de carbono 
$\left(\mathrm{CO}_{2}\right)$ em presença de umidade ao Hidróxido de Cálcio $\left(\mathrm{Ca}(\mathrm{OH})_{2}\right)$, denotando um concreto vivo e sadio, inserido em um ambiente particularmente agressivo ao cimento Portland, orla marinha, brisa rica em sais de cloro, que se precipitam na superfície a espera de umidade, abundante no local, para penetrar no concreto e, se possível, atingir as armaduras e instalar as células de corrosão. O que acontece onde o cobrimento da armadura foi mínimo, como mostrado abaixo na figura 2.

Figura 2 - Aspecto da primeira viga circular aérea, no térreo, da torre circular. Corrosão mais acentuada no semicírculo voltado para a orla.

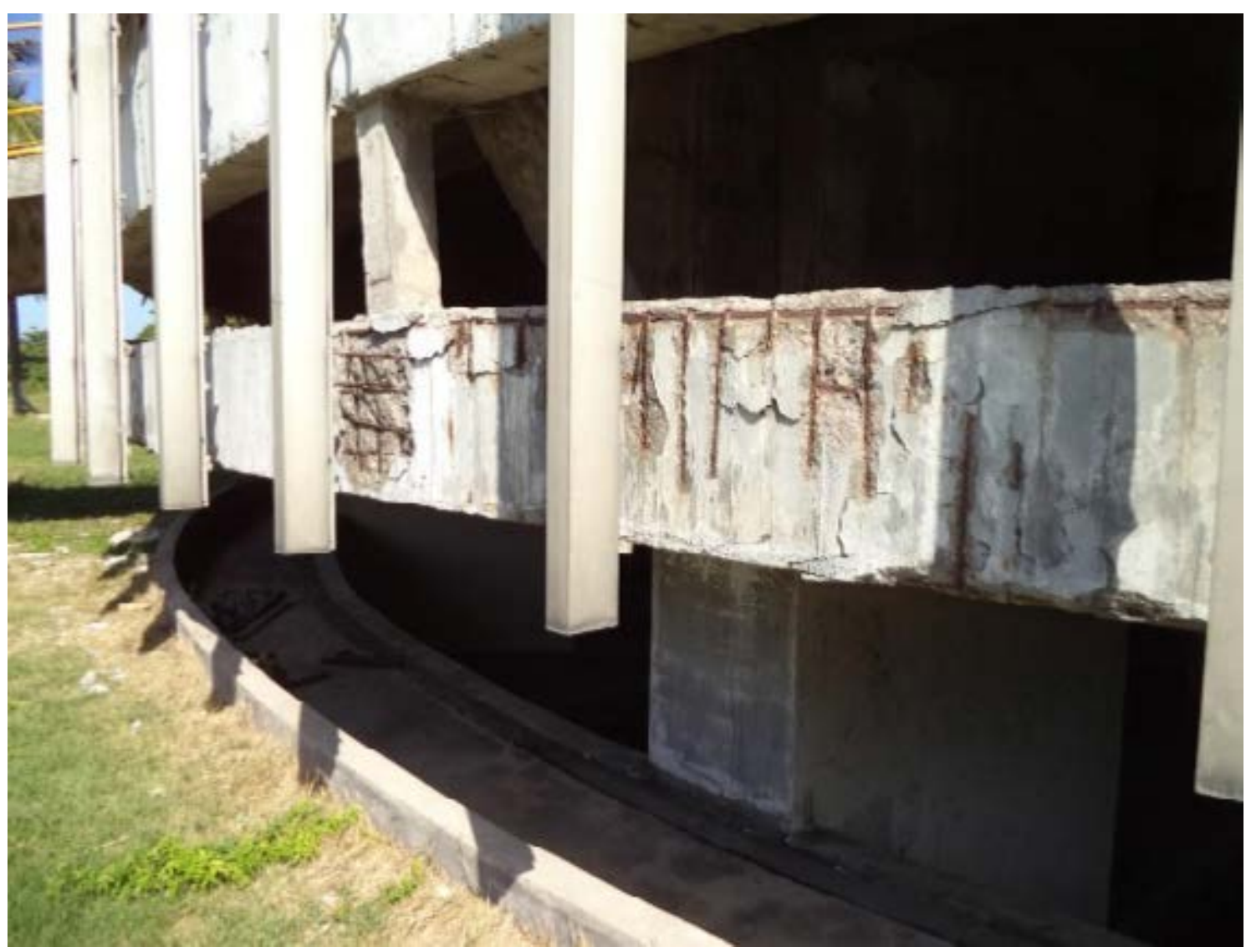

Fonte: (Do autor)

Os procedimentos executivos dos reparos são: Apicoamento dos pontos com martelos pneumáticos ou elétricos até a profundidade da armadura afetada e corroída. Limpeza com jatos de água com alta pressão, para garantia de qualidade da superfície de aderência do reparo. A armadura recebe pintura protetora e a área apicoada e rebaixada preenchida preferencialmente com graute. Quando conveniente, o reparo poderá ser 
feito com argamassa tixotrópica em superfícies voltadas para baixo, fundo de viga e laje ou laterais de viga e pilar.

\subsection{Processo de Restauro}

\subsubsection{Materiais e Equipamentos Utilizados}

Os materiais utilizados para realização deste trabalho foram:

Argamassa polimérica Zentrifix GM2; Inibidor de corrosão Zentrifix KMH; Escova de aço; Trincha; Água potável; Colher de pedreiro; Mareta; Ponteiro e talhadeira; Bomba de 1001; Cimento CP 32; Cimento Branco; Adesivo acrílico; Lixa de ferro grão 60; Verniz poliuretano anti pichação; Verniz acrílico; Tela fachadeiro; Rolo de lã de carneiro; Lona terreiro; Disco de lixa grana 36/60.

Os equipamentos utilizados para realização deste trabalho foram:

Lavadora de alta - Pressão água quente 2200 psi para retirada de pichação e elementos soltos; Andaime tubular para acesso a Estrutura; Martelete perfurador para preparo de argamassa polimérica; Serra Mármore para delimitação de área; Martelete elétrico para demolição de estrutura; Lixadeira 7" para tratamento da superfície de concreto.

\subsubsection{Restauro}

Toda superfície recebeu farto jateamento de água de alta pressão 2200 psi, para retirada de elementos soltos nas áreas que apresentaram pintura remanescente de verniz ou pichação. $O$ jateamento foi feito utilizando agua quente.

Durante a execução dos serviços, constantes exames eram feitos nas peças afetadas, através de testes de percussão, por técnico especializado, com supervisão de Engenheiro para avaliar as anomalias encontradas e determinar a extensão e profundidade dos cortes de concreto eventualmente necessário e sua consequente implicação, nas condições de estabilidade da estrutura foi executada delimitação com serra mármore das regiões com anomalias a ser reparadas, criando figuras geométricas, como abaixo na figura 3. 
Figura 3 - Identificação das patologias

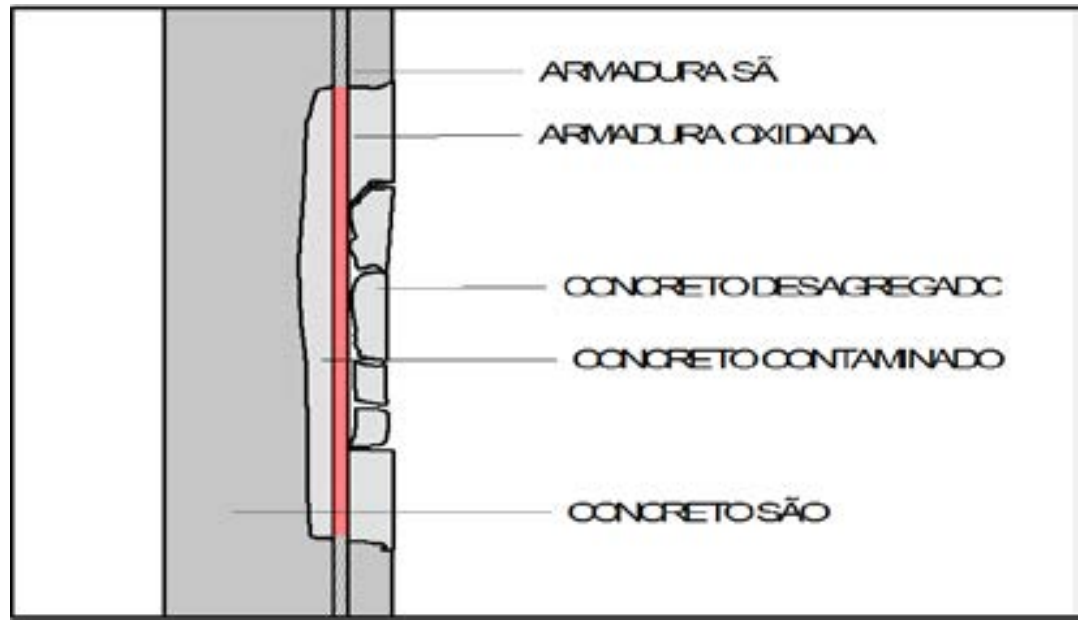

Fonte: (Procedimento de Execução de Serviço - PES. Acervo Hotel Nacional)

Toda peça estrutural que após os exames apresentaram desagregação, sinais de desplacamento do concreto ou ainda com sintomas de oxidação, das barras, foram escarificada com auxílio de rebarbadores, marteletes de baixa potência ou manualmente, com uso de ponteiros e marretas, até atingir a camada de concreto são, homogênea, bem como as armaduras íntegras e livres de corrosão.

Todas as superfícies de concreto de baixa resistência foram devidamente apicoadas com a remoção da nata de cimento e retirada de todo o concreto microfissurado nas operações de corte, com utilização de ferramentas manuais ou elétricas, de maneira a formar a base ideal que permita perfeita aderência entre o concreto remanescente e o material de recomposição utilizado, como apresentado nas figuras 4 e 5 . 
Figura 4 - Limpeza da área

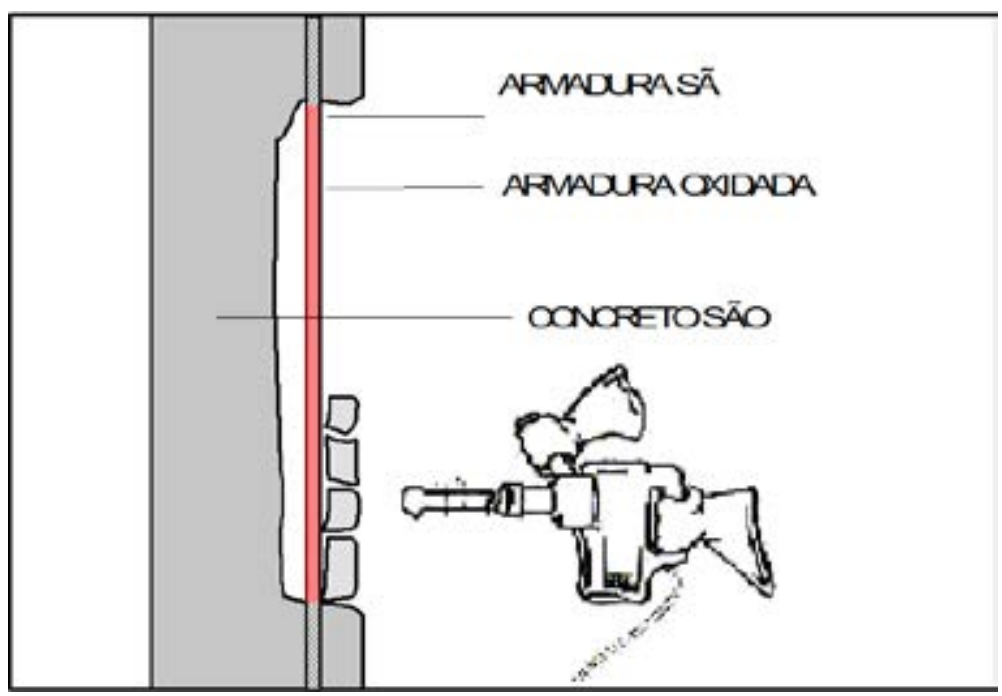

Fonte: (Procedimento de Execução de Serviço - PES. Acervo Hotel Nacional)

Figura 5 - Limpeza da área

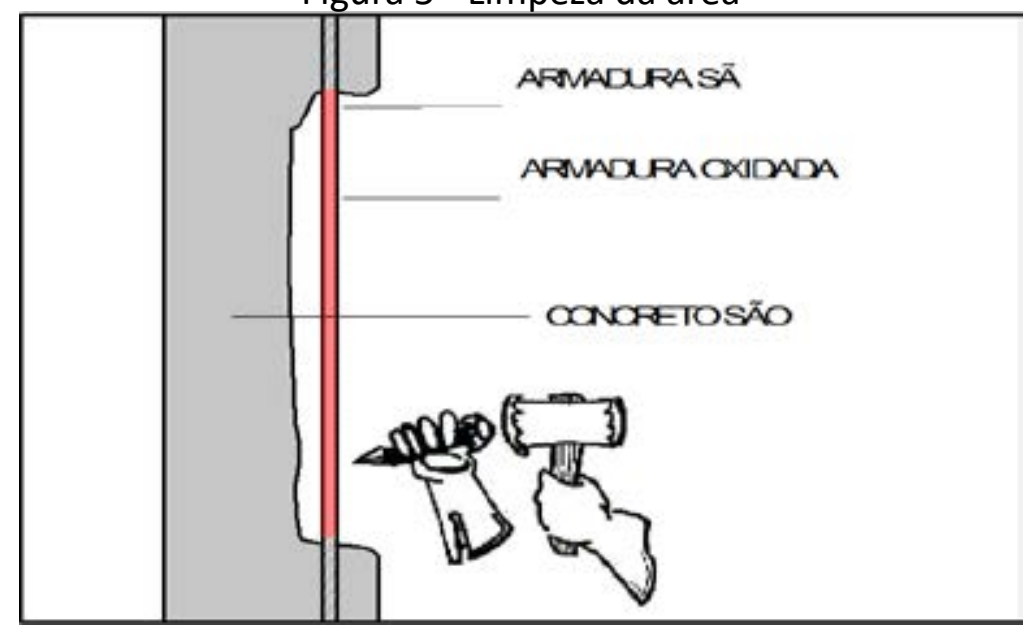

Fonte: (Procedimento de Execução de Serviço - PES. Acervo Hotel Nacional)

Foi feita limpeza das superfícies das armaduras, com escovas de cerdas de aço manualmente, para eliminação de carepas de oxidação e substâncias nocivas ainda aderentes à massa de aço.

As armaduras corroídas e ainda aproveitáveis, por não apresentarem redução de seção superior a 10\% (dez percentuais), após a remoção de carepas de oxidação e sujeiras, foram tratadas com produto base cimenticio monocomponente Zentrifix $\mathrm{KMH}$ 
como inibidor de corrosão, aplicado através de trincha ou pincel, conforme especificação do fabricante do produto adotado.

Após a limpeza das partes reconstituídas, aplicou-se, uma camada de Zentrifix $\mathrm{KMH}$, revestimento protetor corrosivo e ponte de aderência, próprio para garantir a aderência perfeita entre o concreto remanescente e a argamassa de preenchimento, de modo a eliminar o surgimento de micro fissuras por retração da argamassa e logo após a aplicação da ponte de aderência aplicou-se argamassa Zentrifix $\mathrm{GM} 2$, reconstituindo a seção original das peça. Este procedimento foi adotado para preenchimento de cavidades com espessura até $25 \mathrm{~mm}$ por camada com máxima de $100 \mathrm{~mm}$, conforme abaixo nas figuras 6 e 7 .

Figura 6 - Tratamento superficial da armadura

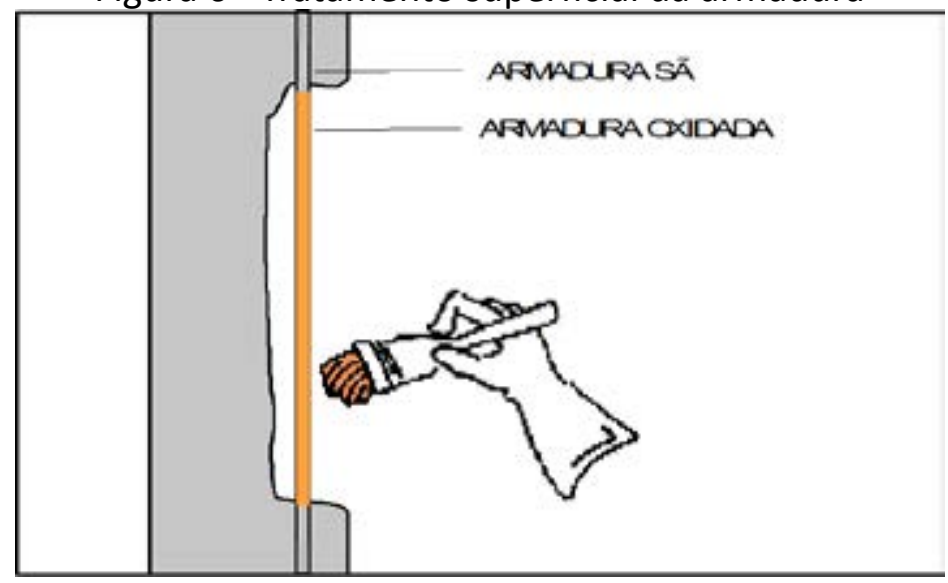

Fonte: (Procedimento de Execução de Serviço - PES. Acervo Hotel Nacional)

Figura 7 - Reconstituição da área tratada

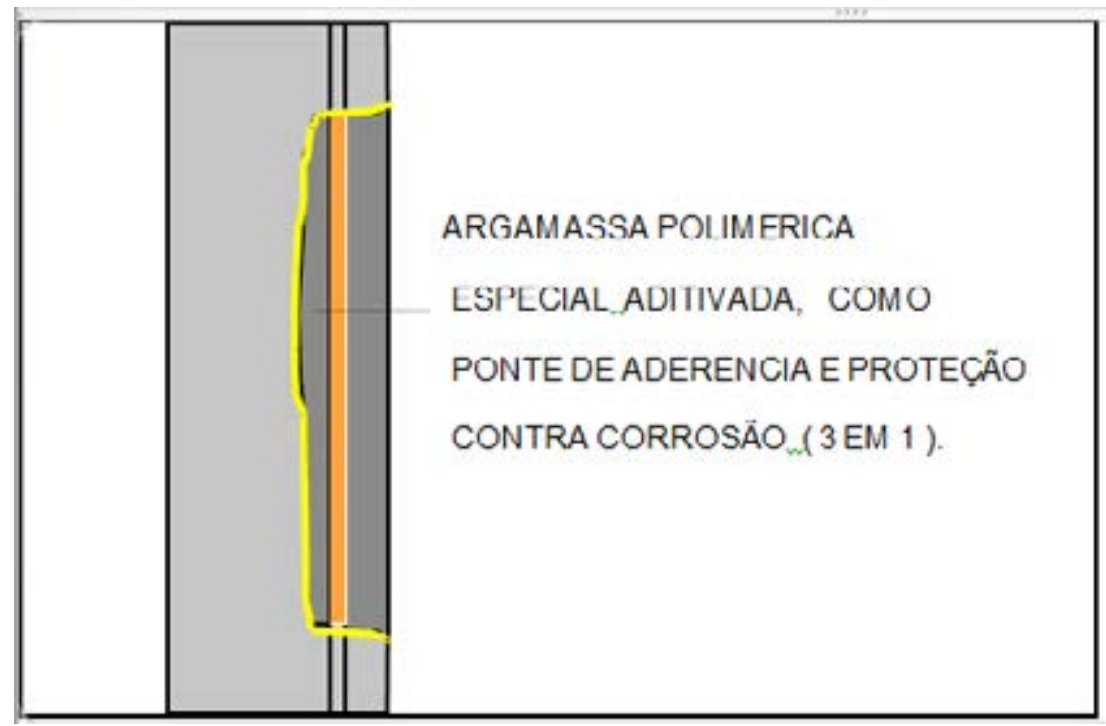


Fonte: (Procedimento de Execução de Serviço - PES. Acervo Hotel Nacional)

Abaixo nas figuras 8 a 13, são apresentados registros feitos "in loco" do "antes e depois" do tratamento das armaduras.

Figura 8 - Pilar da passarela que liga o Jardim a Torre. Antes do tratamento das armaduras

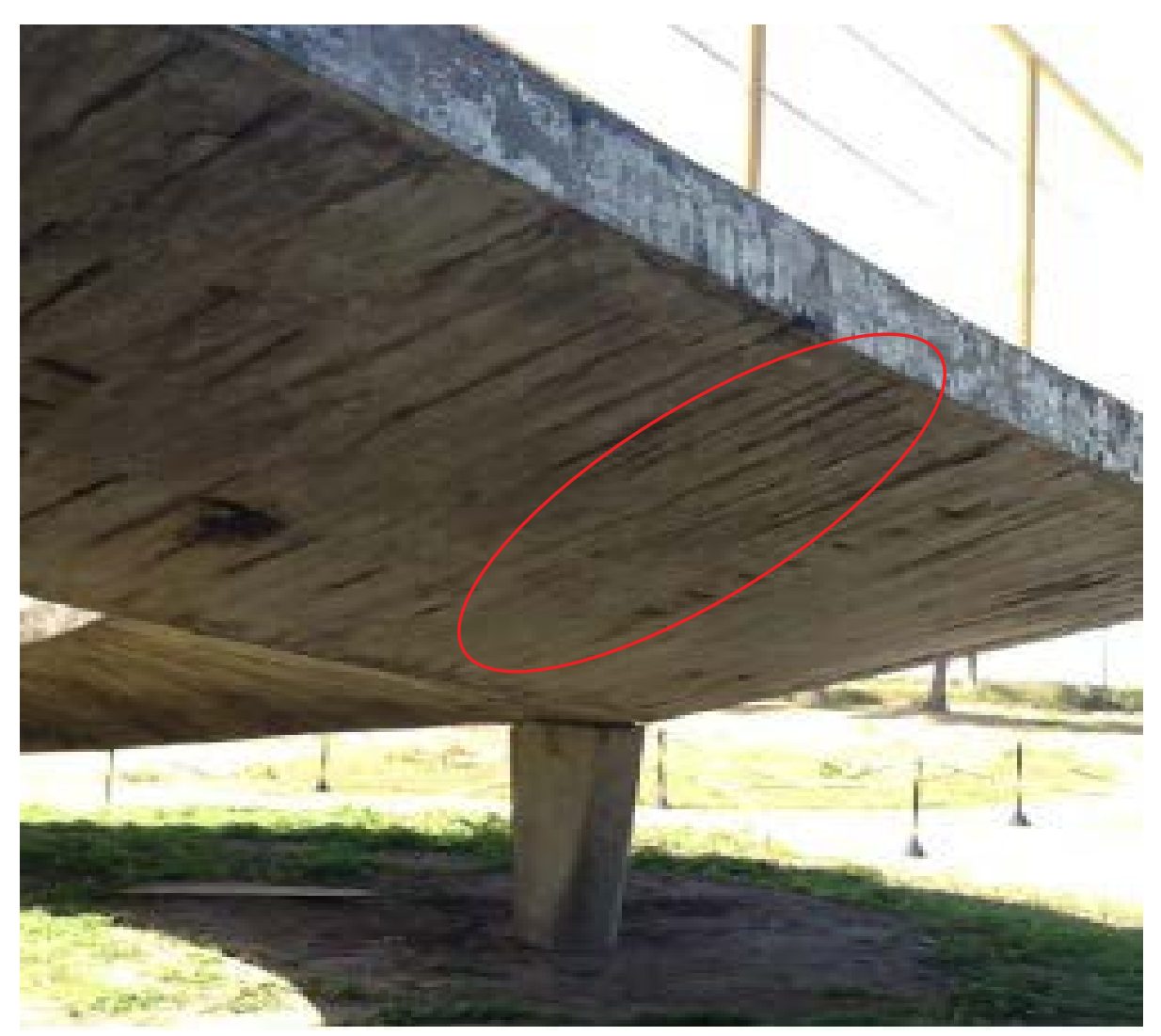

Fonte: (Autor) 
Figura 9 - Pilar da passarela que liga o Jardim a Torre. Depois do tratamento das armaduras

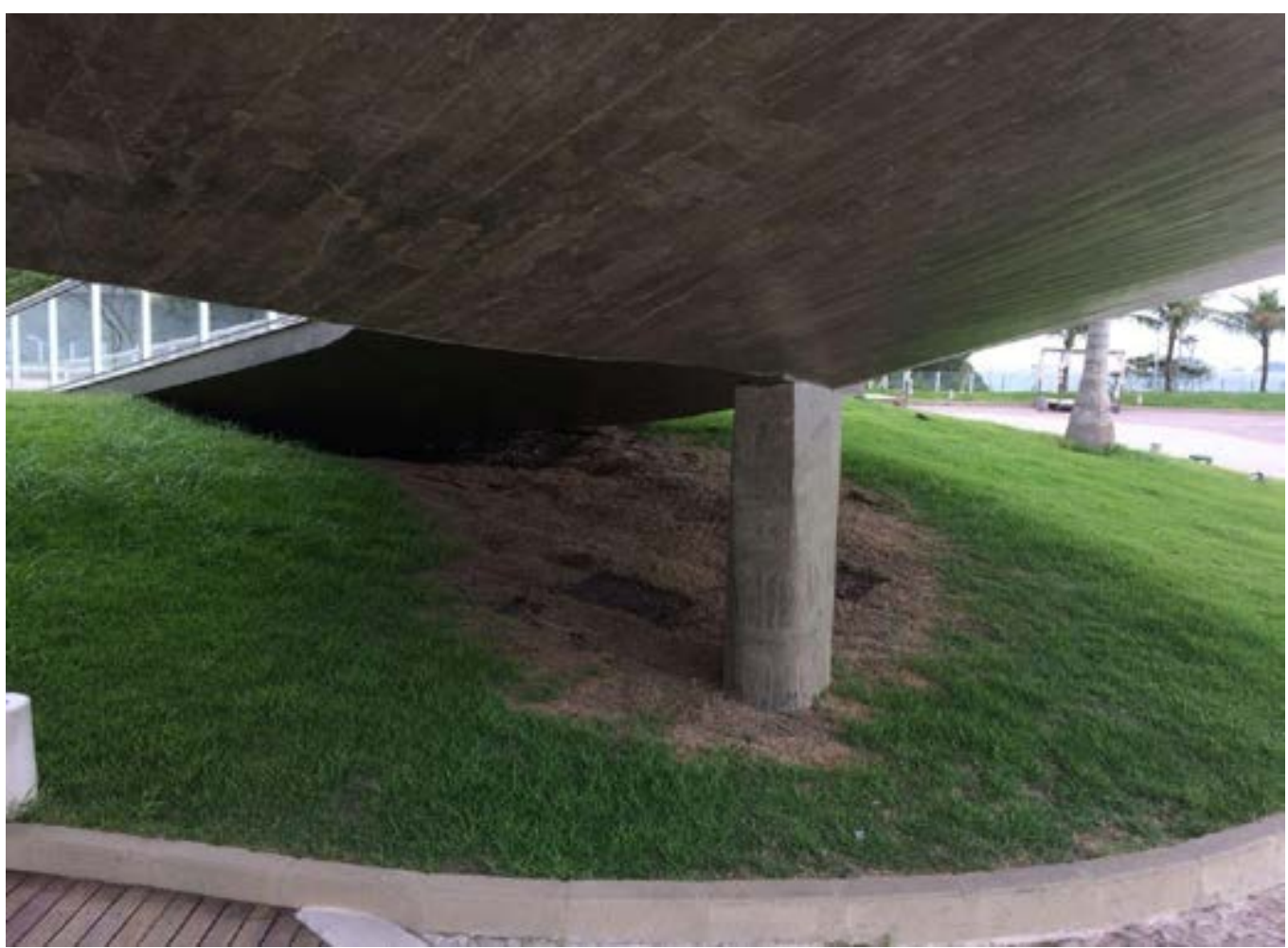

Fonte: (Autor)

Figura 10 - Visto da laje do Rooftop antes do tratamento das armaduras

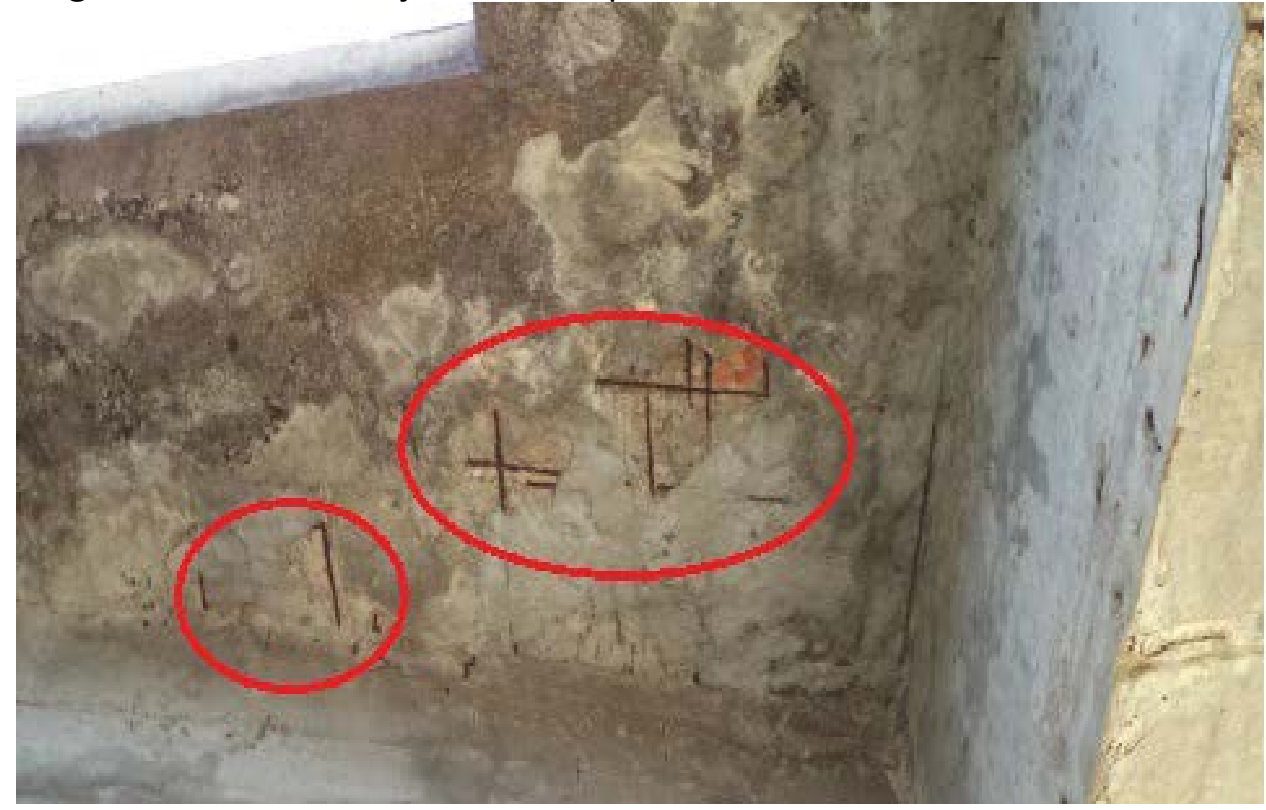

Fonte: (Autor) 
Figura 11 - Visto da laje do Rooftop depois do tratamento das armaduras

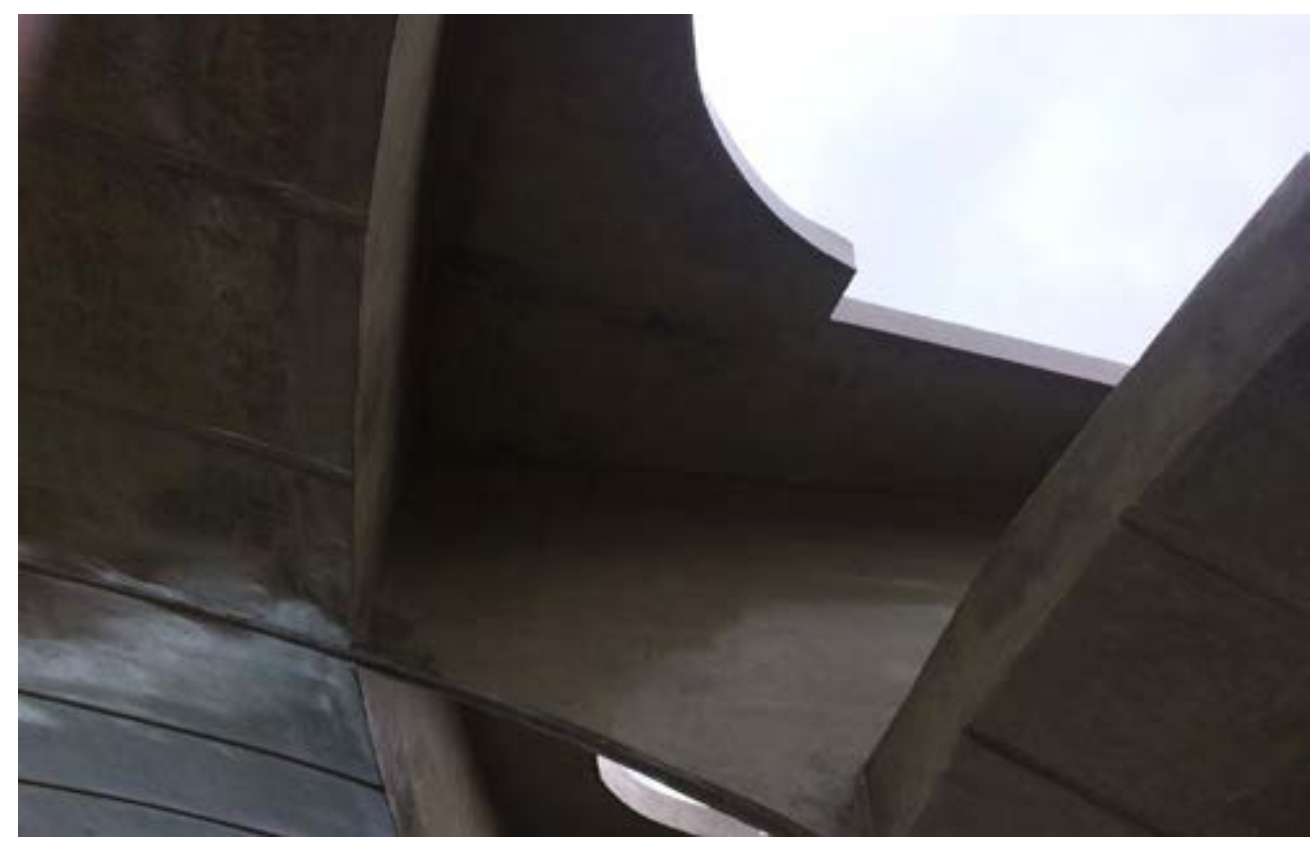

Fonte: (Autor)

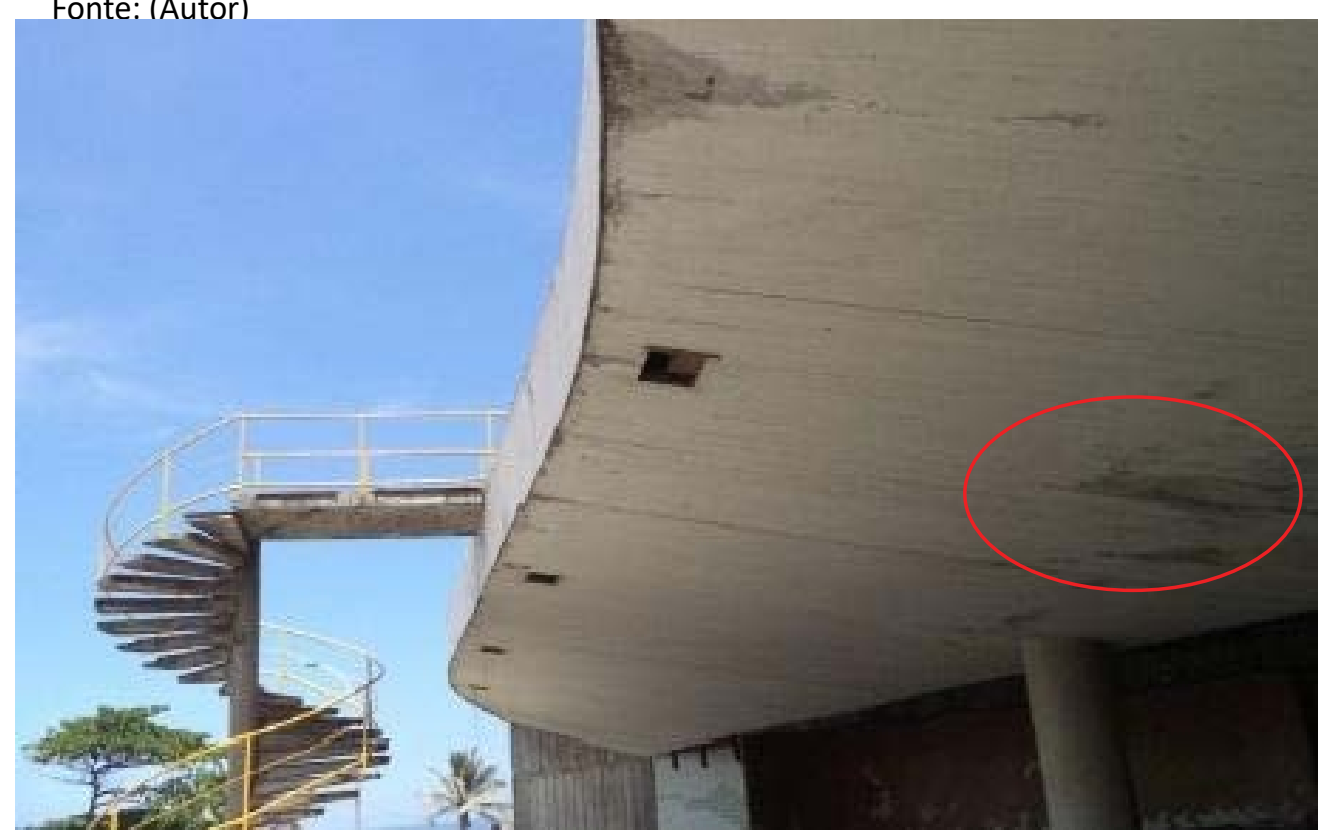

Fonte: (Autor) 
Figura 13 - Grande Marquise frontal do Hotel depois do tratamento

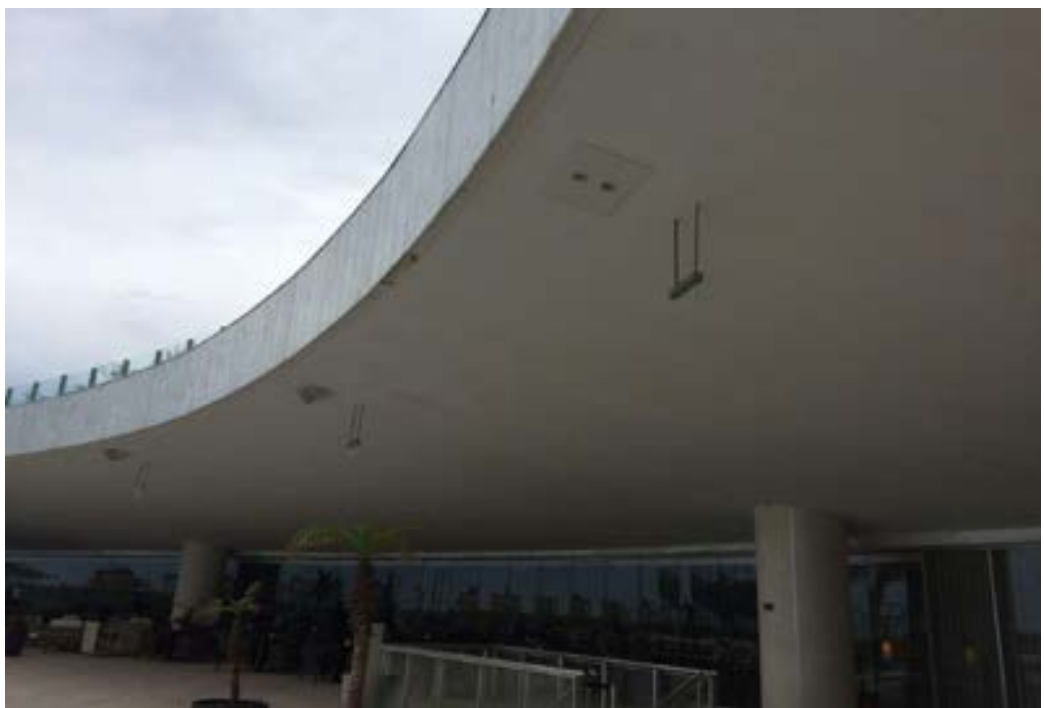

Fonte: (Autor)

\section{CONCLUSÃO}

Este trabalho tem o objetivo de apresentar um estudo teórico e um estudo de caso sobre as patologias nas estruturas de concreto armado, pontuando seus contratempos que aumentam o custo de uma edificação que podem ser reduzidos, caso sejam vistos com maior atenção na criação de seus projetos, especificação e utilização de materiais e até mesmo no uso adequado da estrutura e na sua Manutenção Preventiva.

Observa-se que as manifestações patológicas têm sua origem na maioria das vezes na fase de projeto de uma obra e na falta de cuidado em sua execução trazendo consequências graves na durabilidade das estruturas fazendo com que fenômenos de degradação, como, por exemplo, a corrosão das armaduras se multiplique consideravelmente.

Logo após a verificação e análise das patologias, percebe-se que os procedimentos adotados são semelhantes. Limpeza das armaduras com a remoção da corrosão nas barras, preparo da superfície para liberação das armaduras a serem tratadas, substituição das armaduras, proteção das armaduras e recomposição da geometria das 
armaduras. Por sua vez, o estudo de caso mostra de forma veemente as decorrências da falta de manutenção preventiva em estruturas expostas a ambientes marinhos. Serviu, portanto para classificar os tipos de patologia e formas de como evitá-las, mas deixando como sugestão para trabalhos futuros, temas que possam envolver o tratamento e a recuperação de estruturas.

\section{REFERÊNCIAS}

ABCP. Guia básico de utilização de Cimento Portland, Dez. 2002

AMORIM, Kelly. O Desempenho da Construção Civil nas duas décadas do plano Real e desempenho recente, Ago. 2014. Disponível em <http://construcaomercado17.pini. com.br/negocios-incorporacao-construc. aspx > Acesso em: 16 Nov. 2017.

Associação Brasileira de Normas técnicas. NBR 6118: Projeto de estruturas de concreto. Procedimento. Disponível em: <http://www.pucrs.br/feng/civil/professores/ giugliani/ciencia_dos_materiais_notas_de_aula_13_Concreto_NBR6118_Comentarios. pdf >. Acesso em: 16 nov. 2017.

BRASIL, Lei no 10460, de 10 de janeiro de 2002.

GIL, A. C. Métodos e Técnicas de Pesquisa Social. São Paulo: Atlas, 2007, 208p.

HELENE, P. R. L. Manual para reparo, reforço e proteção de estruturas de concreto. 2. ed Sao Paulo: PINI, 1992. $213 p$

HELENE, P. R. L. (2001). Introdução da vida útil no projeto das estruturas de concreto NB/2001. WORKSHOP SOBRE DURABILIDADE DAS CONSTRUÇÕES. Novembro. São José dos Campos.

IBRACON. Revista IBRACON. Concreto: Material construtivo mais consumido no Mundo. Disponível em: <http://www.ibracon.org.br/publicacoes/revistas_ibracon/rev_ construcao/pdf/Revista_Concreto_53.pdf> Acesso em 18 Nov. 2017 
MARCELLI, M. Sinistros na construção civil: causas e soluções para danos e prejuízos em obras - São Paulo: Pini, 2007.

MARCELLINO, N. AECWEB. Concreto armado é solução durável e econômica. Disponível em: <https://www.aecweb.com.br/cont/m/rev/concreto-armado-e-solucao-duravel-eeconomica_6993_0_1>. Acesso em: 18 nov. 2017.

MEDEIROS, Marcelo. Corrosão do concreto é causada por umidade e gases nocivos. Disponível em: <https://www.aecweb.com.br/cont/m/rev/corrosao-do-concreto-ecausada-por-umidade-e-gases-nocivos_6412_0_1> Acesso em 16 Nov. 2017

PETRUCCI, E.G.R. PAULON, V.A. Concreto de cimento Portland.10. ed Porto Alegre: Globo, 1983. 307p ISBN (Broch.)

PIANCASTELLI, E.M. AECWEB. Patologias do concreto. Disponível em: <https://www. aecweb.com.br/cont/m/rev/patologias-do-concreto_6160_10_0>. Acesso em: 21 nov. 2017.

SBARDELINI, A.; PEREIRA, A. N.; CISOTTO, D. Inspeção, manutenção e recuperação de marquises e sacadas. Pós-Graduação Especialização em Patologias nas Obras Civis. Universidade Tuiuti do Paraná. 2006.

SOUZA, V.C.M.; T., Ripper. Patologia, Recuperação e Reforço de Estrutura de Concreto. São Paulo: Pini, 2009. 262p. 